\title{
Fetal posterior cerebral artery duplication and anterior cerebral artery triplication
}

\author{
Akira Uchino ${ }^{1}$ (1) \\ Received: 15 July 2020 / Accepted: 8 September 2020 / Published online: 14 September 2020 \\ ○) Springer-Verlag France SAS, part of Springer Nature 2020
}

Dear Sir,

I read with great interest the recent online-first article titled "Fetal posterior cerebral artery duplication, true fetal posterior cerebral artery variation and trifurcation anterior cerebral artery association" by Kaplanoglu et al. [1] published in Surgical and Radiologic Anatomy (E-pub ahead of print, https://doi.org/10.1007/s00276-020-02523-6). The fetal posterior cerebral artery duplication has been called "hyperplastic anterior choroidal artery", its prevalence was reported as $2.3 \%$ on catheter angiography [2] and $0.55 \%$ on magnetic resonance (MR) angiography [4]. This discrepancy between the prevalence of catheter and MR angiography studies may be due to the low spatial resolution of MR angiography.

The authors stated that trifurcation of the anterior cerebral artery (ACA) is a rare variation. Using MR angiography, however, we previously reported that the prevalence of the triplicated ACA as 3.0\%, not rare [3].

In addition, there is simple erratum, "vein" is "artery" on the first line of the Discussion.

\section{Compliance with ethical standards}

Conflict of interest The author declares that I have no conflict of interest.

\section{References}

1. Kaplanoglu H, Turan A, Kaplanoglu V, Karacif O (2020) Fetal posterior cerebral artery duplication, true fetal posterior cerebral artery variation and trifurcation anterior cerebral artery association. Surg Radiol Anat. https://doi.org/10.1007/s00276-020-02523 -6(Publishedonline:01July2020)

2. Takahashi S, Suga T, Kawata Y, Sakamoto K (1990) Anterior choroidal artery: angiographic analysis of variations and anomalies. Am J Neuroradiol (AJNR) 11:719-729

3. Uchino A, Nomiyama K, Takase Y, Kudo S (2006) Anterior cerebral artery variations detected by MR angiography. Neuroradiology 48:647-652

4. Uchino A, Saito N, Takahashi M, Okano N, Tanisaka M (2016) Variations of the posterior cerebral artery diagnosed by MR angiography at 3 tesla. Neuroradiology 58:141-146

Publisher's Note Springer Nature remains neutral with regard to jurisdictional claims in published maps and institutional affiliations.
Akira Uchino

auchino0528@gmail.com

1 Department of Radiology, Saitama Sekishinkai Hospital, 2-37-20 Irumagawa, Sayama, Saitama 350-1305, Japan 